\title{
Experimental Study to Predict Torsional and Bending Strength of Hybrid Aluminium-Woven Fabric Composite Tubes After Low Velocity Impact
}

\author{
Pankaj Choudhary ${ }^{*}$, Prof. U.K. Joshi** \\ "Research Scholar, Department of Mechanical Engineering Jabalpur Engineering College, Jabalpur, India \\ ${ }^{* *}$ Associate Professor, Department of Mechanical Engineering Jabalpur Engineering College, Jabalpur, India
}

\begin{abstract}
In this experimental study a hybrid composite shaft was fabricated by wrapping 200 GSM carbon and 450 GSM E-glass woven fabric fibre with 7121 PA matrix material, completely around aluminium tube with manufacturing method in which hand layup method aided with high pressure compressed air is productively used for the purpose that woven fabric could conform to curved surfaces. A pendulum type drop weight test setup was construct which is able to produce low-velocity transverse impact damage on composite specimens. A total of twelve specimens were manufactured in which three specimens from each type of composite material and three bare aluminum tubes are impacted at energy level of $10.5 \mathrm{~J}$ on two consecutive points whish are 50 $\mathrm{mm}$ apart along the longitudinal axis of specimen, eighteen specimens in total, were tested under torsion, three point and four point bending test. For a low velocity impact, it is notice that invisible cracks develops in carbon/glass fibre along with small conical impression occur in aluminum tube in hybrid aluminum composite tubes. Load-deflection \& torque-angle of twist relation data were documented for with and without impact damage specimens and compare these data.
\end{abstract}

Keywords: Hybrid Composite, Low Velocity Impact, Torsion, Three \& Four Point Bending

\section{INTRODUCTION}

Composite material possess superior properties than the metallic structure because it has advantages of light weight, stronger, tougher, better aesthetics, rust-free, higher damping properties etc. Hybrid aluminium/composite tubes regarded as tomorrow's materials due to their potentials applications in truss members, conduits pipes, antennae, robot arms, printing rollers, tube structures for sports, automobile, landing gears for copter and in house structural parts etc. Woven roving fabric fibres used in developing a hybrid, carbon/glass fibre-reinforced, epoxy composite automotive drive shaft by $[1,2]$ to find out the effect of fibre orientation angles and stacking sequence on the torsional stiffness, natural frequency, buckling strength and fatigue life of composite drive shaft. The maximum torsion capacity of the hybrid aluminium (AA6063-T4) /composite shaft significantly affected by different winding angle, number of layer, stacking sequences and with $45^{\circ}$ layers can withstand higher static torsion compared to $90^{\circ}$ in all cases studied by [3]. According to [4] increasing the number of composite layers, changing the stacking sequence would increase the Bending fatigue strength and stacking sequence $[+/ 45 / 45]_{3 \mathrm{~s}}$ has the highest fatigue strength for a hybrid aluminium(AA6063) /composite drive shaft. Substituting composite structures for conventional metallic structures by a hybrid onepiece drive shaft composed of carbon fibre epoxy composite and aluminium tube was manufactured by co-curing the carbon fibre wrapping on the outer surface of aluminium(6061-T6) tube[5] and on the inner surface of an aluminium (6061-T6) tube [6] to determine the optimal stacking sequence of the composite layer by considering the thermal residual, it was found that the developed drive shaft had $75 \%$ mass reduction, $160 \%$ increase in torque capability. The maximum torsion capacity of filament wound kenaf yarn fibre reinforced unsaturated polyester composite hollow shafts for different winding angles and aluminum (AA6063-T4) reinforcement was investigate [7]. Angular velocities of $0.1 \% \mathrm{~min}$ and $5 \%$ min were used as torsion test speeds and effect of torsional strain-rate and lay-up sequences on the performance of hybrid composite shafts was investigated [8].Torsional stability, effects of boundary conditions, fibre orientation and stacking sequence on the mechanical behaviour of composite drive shafts is performed by [9] and show that the boundary conditions of the shaft do not have affects but fiber orientation and stacking sequence strongly affects the bucking torque. [10] deals with the optimization of HS carbon/epoxy hybrid composite drive shafts operating at subcritical or supercritical speeds, using a genetic algorithm. [11] suggested residual torsional properties of E-glass/epoxy, carbon/epoxy and E-glass-carbon/epoxy hybrid composite shafts subjected to impact loadings at 5 , 10,20 and $40 \mathrm{~J}$ energy levels. The residual torsional 
strength and effect of torsional loads on the damage introduced by $7 \mathrm{~J}$ transverse impacts on unidirectional carbon/epoxy cylindrical specimens under various torsional preloads examined, the result shows that impacts on unloaded, preloaded at $65 \%$ and $130 \%$ RTS, AP specimens produce an equivalent delamination size of 8,15 and $50 \mathrm{~mm}$ respectively \& QI specimens produce an equivalent delamination size of 12,18 and $50 \mathrm{~mm}$ respectively by $[12,13]$. [14] analyze fatigue behavior of unidirectional GFRP composites under in-phase combined torsion/bending loading on constant-deflection fatigue machine with frequency of $25 \mathrm{~Hz}$ and results showed that, the unidirectional GFRP composites have poor torsional fatigue strength than pure bending fatigue strength. A test set-up designed and manufactured [15] to produce low-velocity impact damage in glass fibre/epoxy cylindrical tubes at energy levels between $3.5 \mathrm{~J}$ and $8.5 \mathrm{~J}$ and point-like, regular and irregular cracks and delamination zones caused by impact were observed. [16] prepares polyurethane based glass fibre, Kevlar 49, and carbon fibres fabric composite shaft and carried out triple point bending tests to predict Stress vs deflection curve behaviour. Based on the above literature review, it is found that $[1,2]$ analyse woven roving fabric fibres based composite automotive drive shaft for torsional stiffness, natural frequency, buckling strength and fatigue life and [16] carried out triple point bending test. Some researchers [3, 4, 5, 6, 7] have done investigation on hybrid aluminium/composite drive shaft and [11, 12, 13, 15] conduct analysis of composite shaft after impact damages. This experimental work was carried out to compare residual strength of damaged and undamaged hybrid aluminium-woven fabric composite tube specimens under static torsion, three point and four point bending tests. The specimens used in the experiment were fabricated with a manufacturing method in which combination of hand layup method and high pressure compressed air were used. Some researchers $[6,11,12]$ designed and used end fitting method for torsional test, so in this study such designing of end fitting was not considered.

\section{PROBLEM STATEMENT}

When components made up of composite materials, perform their desired function during its working hours, it is may be subjected to torsion and bending loads. Low velocity impact damage is an accidental occurrence that happens frequently on any structures and the sources of such impact is flying fragment, scraps or tools hit the components during operation, maintenance, or assembly work, these impact damages significantly affects the mechanical strength of composite structure[11,15]. To achieve wider application scope of composites structure, it is essential to investigate the damage behaviour and residual strength under low-velocity impact loads $[11,12,13,15]$. In the study, composite tubes were first damaged by low velocity impact and then tested.

\section{SPECIMEN FABRICATION AND GEOMETRY}

The aluminum (Al) tube (AA6063-T4) used for this experimental study was of outer diameter $\left(\mathrm{d}_{\mathrm{o}}\right)=$ $18.3 \mathrm{~mm}$, inner diameter $\left(\mathrm{d}_{\mathrm{i}}\right)=16.13 \mathrm{~mm}$ and length $\mathrm{l}=180 \mathrm{~mm}$. The mechanical properties of aluminum tube used in this work are mention in Table 1 [3]. Two layers of carbon and glass woven fabric were wrapped around aluminum tube with a manufacturing method in which combination of hand layup method and high pressure compressed air were utilized. Carbon and glass woven fabrics with the surface density of 200 GSM (gram per square meter) and 450 GSM respectively, are used with 7121 PA resin material to manually fabricate total twelve composite tubes. 2-D plain weave woven fabrics [0/90] lay-up used in the project are shows Fig. 1. Fabric parameters of the fibers are listed in Table 2 and in this table, $b_{w} \& b_{f}$ are the strand breath, and $c_{w} \& c_{f}$ are the gap between two consecutive strands. f and $w$ superscript designate the fill and warp direction of the plain weave woven fabric, respectively. Table 3 shows the mechanical properties of glass and carbon fibers [17]. 7121 Phthalic Anhydride (GP) resin matrix material which is pre-promoted with cobalt $6 \%$ (in this case $1 \%$ by mass) and methyl ethyl ketone peroxide (MEKP) hardener were used in this work in proportion of $4: 1$ by volume respectively. In the first step, resin and hardener are mixed in a measuring cup and manually stirred. In the second step, prepared mixture was applied on woven fibre layer and wrapped on aluminium tube. The wrapped aluminum tube had been covered with plastic sheet and put into pressure cylinder for the purpose that woven fabric could conform to curved surfaces and produce smooth surface, in the third step. These specimens are vertically placed at the center of pressure cylinder. The gate valve is attached to the side of the pressure cylinder which in turn is then connected to the compressed air stored vessel via pipe. In the last step, during air compression process the air pressure was maintained between 0.62-0.69 MPa for 5 minutes, after releasing the pressure, these tubes are removed from pressure cylinder and left for 24 hours for curing process under room temperature. The arrangement of compressor unit and pressure cylinder is shown in Fig. 2. Completed twelve specimens fabricated by above mention technique are shown in Fig. 3. 

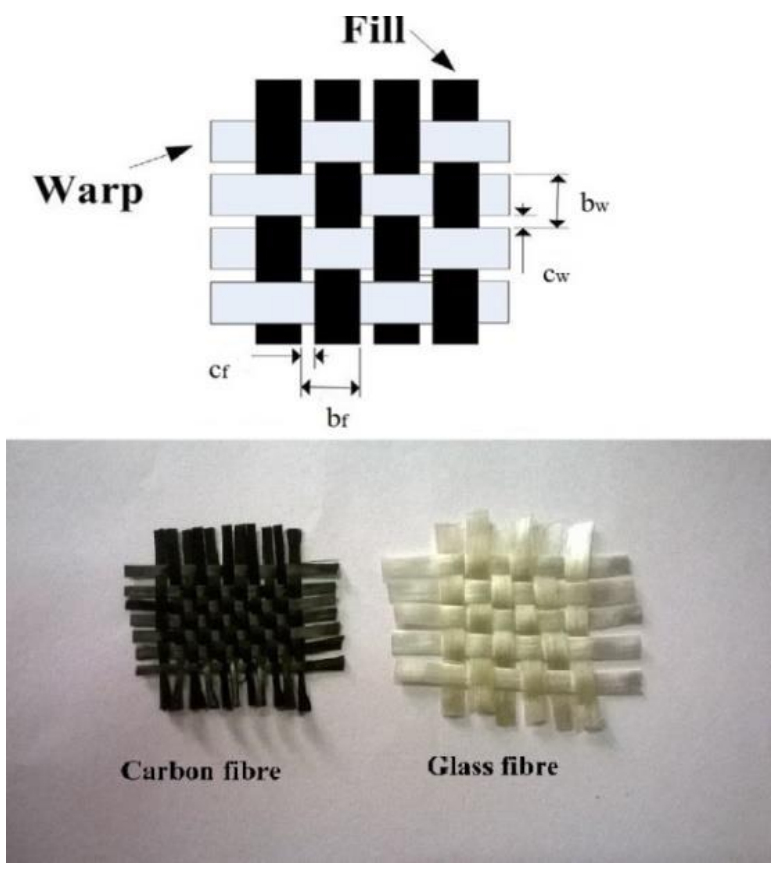

Fig. 1: 2-D plain weave woven fabrics

The thicknesses of the woven fabrics were measured to be:

Carbon woven fabric thickness $=0.2 \mathrm{~mm}$

Glass woven fabric thickness $=0.6 \mathrm{~mm}$

The cylindrical specimens have the following characteristics:

Specimens are made of aluminum/E-glass fibre:

Specimen length: $180 \mathrm{~mm}$

Average inner diameter: $16.13 \mathrm{~mm}$

Average outer diameter: $20.25 \mathrm{~mm}$ and

Specimens are made of aluminum/carbon fibre:

Specimen length: $180 \mathrm{~mm}$

Average inner diameter: $16.13 \mathrm{~mm}$

Average outer diameter: $19.72 \mathrm{~mm}$

Table 1: Mechanical Properties of Aluminum (AA6063-T4)

\begin{tabular}{|l|l|}
\hline Tensile modulus (GPa) & 69 \\
\hline Shear modulus $(\mathrm{GPa})$ & 26.5 \\
\hline Poisson's ratio & 0.3 \\
\hline Density $\left(\mathrm{kg} / \mathrm{m}^{3}\right)$ & 2700 \\
\hline Ultimate tensile stress $(\mathrm{MPa})$ & 131 \\
\hline Yield strength $(\mathrm{MPa})$ & 69 \\
\hline Shear strength $(\mathrm{MPa})$ & 69 \\
\hline
\end{tabular}

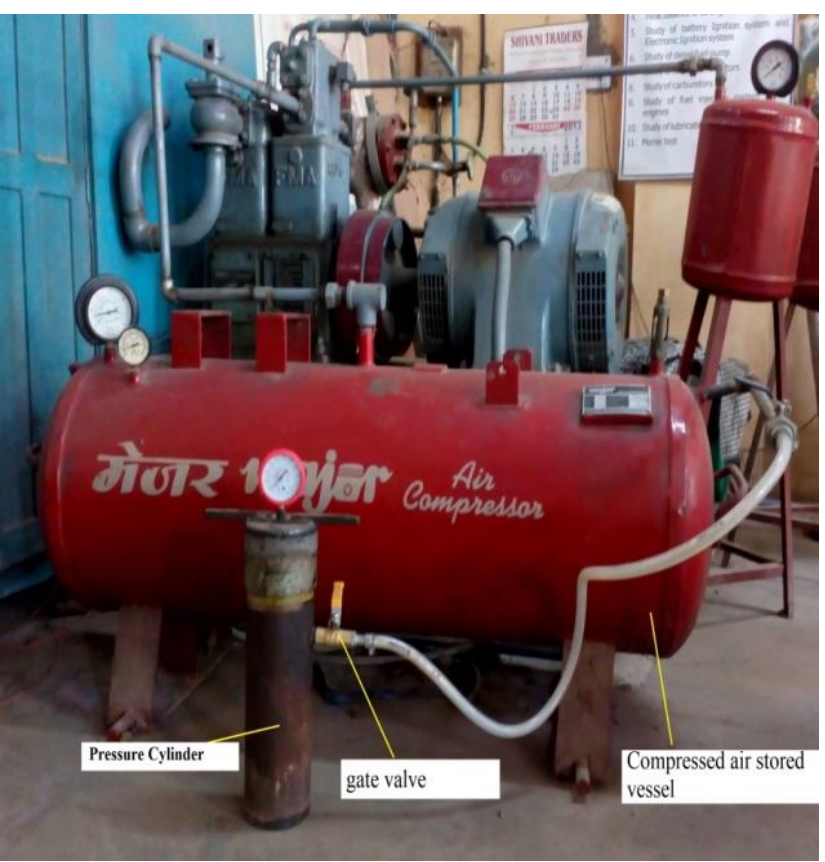

Fig. 2:Arrangement of compressor unit and pressure cylinder

Table 2:Dimension of 2-D Plain Weave Woven Fabric Structure

\begin{tabular}{|l|l|l|l|l|}
\hline Material & $\mathrm{b}_{\mathrm{w}}(\mathrm{mm})$ & $\mathrm{c}_{\mathrm{w}}(\mathrm{mm})$ & $\mathrm{b}_{\mathrm{f}}(\mathrm{mm})$ & $\mathrm{c}_{\mathrm{f}}(\mathrm{mm})$ \\
\hline Glass fibre & 3.60 & 0.70 & 3.60 & 0.70 \\
\hline Carbon fibre & 1.78 & 0.42 & 1.78 & 0.42 \\
\hline
\end{tabular}

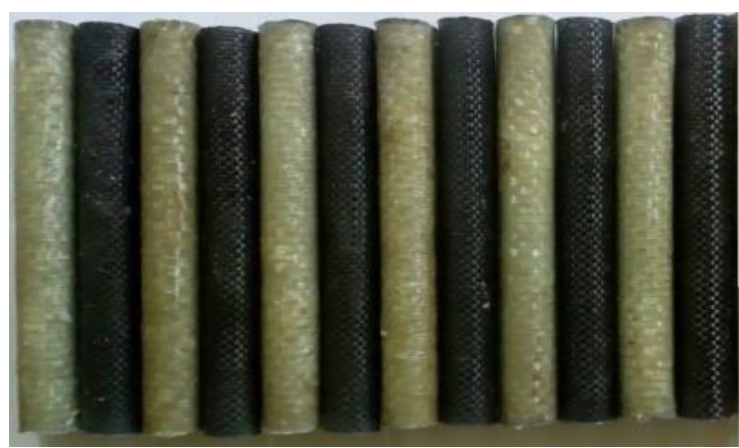

Fig. 3:Hybrid aluminium-woven fabric composite specimens

Table 3: Mechanical Properties of Fibres

\begin{tabular}{|l|l|l|l|l|}
\hline Properties & $\begin{array}{l}\text { Specific } \\
\text { gravity }\end{array}$ & $\begin{array}{l}\text { Modulus } \\
(\mathrm{GPa})\end{array}$ & $\begin{array}{l}\text { Strength } \\
(\mathrm{MPa})\end{array}$ & $\begin{array}{l}\text { Percentage } \\
\text { tensile } \\
\text { elongation }\end{array}$ \\
\hline E-glass & 2.60 & 72 & 3450 & 4.8 \\
\hline Carbon & 1.8 & 230 & 2450 & 1.1 \\
\hline
\end{tabular}




\section{DROP WEIGHT TEST SET-UP AND IMPACT TEST DETAILS}

A Pendulum type drop weight impact set-up was designed and constructed to perform the low velocity transverse impact for this study see Fig. 4. The test set-up mainly consists of an impactor, base plate; V shaped specimen holder, two bearing, thin hollow connecting rod and table for mounting base plate and specimen holder. The bearings welded on base plate, an axle passed through the bearings, one end of connecting rod was welded to axle and other end was welded to impactor. The base plate and specimen holder was mounted on table to restrict it from sliding during impact. The impactor tip has conical shape geometry and total mass of $1.7 \mathrm{~kg}$, made using hardened steel has enough hardness to avoiding any deformation of the impactor tip during the test. A timer device was used to measure time taken by the impactor to travel a curved distance subtending approximately $32-33^{\circ}$ angle. This was used to calculate the rotational kinetic energy. The total impacted energy is the sum of potential energy and rotational kinetic energy. The effective height of dropping impactor was $478 \mathrm{~mm}$. The specimen tube was held firmly in place on holder in its full length from both sides, so uniform distribution of the load on the contact area occurs. The impactor drops by gravity fall and the damage was occurring by hitting specimen in transverse direction. Three specimens from each of E-glass, carbon and bare aluminium tube are impacted at energy levels $10.5 \mathrm{~J}$ on two consecutive points of $50 \mathrm{~mm}$ apart along the

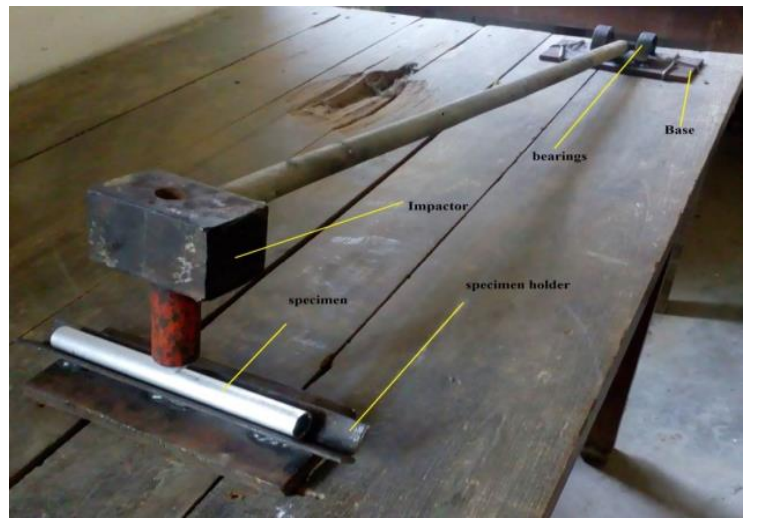

Fig. 4:Pendulum type drop weight setup

longitudinal axis. The two damage points are $25 \mathrm{~mm}$ away from center point of specimen. For a low velocity impact, it is notice that invisible cracks develops in carbon/glass fibre along with small point impression occur in aluminium tube in hybrid aluminium composite tubes and deep conical shaped impression occurs in bare aluminium tubes. These impacted damage specimens are shown in Fig. 5.

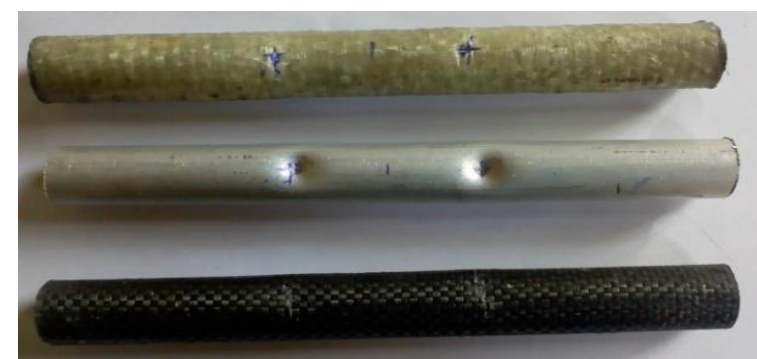

Fig. 5:Specimens after impact

\section{EXPERIMENTAL SETUP}

\subsection{Torsion Test}

The TT type torsion testing machine serves for conducting test in torsion for six specimens and was located at the material testing laboratory of Department of Mechanical Engineering, JEC Jabalpur, India. The machine is equipped with pendulum dynamometer, a recording device for registering torque-twist diagram. The accuracy of the torque indication is $\pm 1 \%$ of true torque. Angular velocity of $1.5^{\circ} / \mathrm{min}$ was used as torsion test speeds. The maximum torsion capacity for this experiment is set at $245 \mathrm{Nm}$. The torsion machine with loaded specimen is shown in Fig. 6. Two specimens for each type of hybrid aluminum-woven fabric composite tubes and bare aluminum tube with and without impact damage were tested under torsion. Both gripping length of specimen were drilled to insert a pin throughout them for preventing the specimens from slip during the test. The ends were clamped tightly in the chuck. The length of the specimens under torsion was $120 \mathrm{~mm}$ and gripping length of specimen was $30 \mathrm{~mm}$. Rotating the chuck exert torque on specimen and at the same time torque value indicate on torque indicating dial and angle of twist can be directly on the angle measuring disc. Torquetwist angle values were recorded until specimen failed.

\subsection{Bending Test}

The three-point and four point bending test were conducted on a UTN-10 model universal testing machine and was located at the material testing laboratory of Department of Mechanical Engineering, JEC Jabalpur, India. The length of the samples was $180 \mathrm{~mm}$ and the span between the supports was 150 $\mathrm{mm}$ for both three and four point bending testing. The loading span for four point bending test is $1 / 3$ of the support span. Two specimens for each type of hybrid aluminum-woven fabric composite tubes and bare aluminum tube, with and without impact damage, were tested under three and four point bending. The load-displacement curves were obtained and the samples were loaded until the applied load reached maximum value. The loaded specimen for the three-point were shown Fig. 7 and 
four point bending were shown Fig. 8.The deflection at the loading point was recorded on indicating dial.

\section{RESULTS AND DISCUSSION}

In this research, the effect of transverse low velocity impact damage on torsional and bending strength of hybrid aluminum-woven fabric composite tubes was studied. It is assumed that the specimens were perfectly balanced and there were no damage on the specimen except the damage due to impactor impact.

\subsection{Torsion Strength}

One specimen with no impact damage and one specimen with impact damaged bare aluminum tube were tested under torsion, similarly done for hybrid glass and carbon tubes. It is observed that for specimens without impact were fractured at gauge length and specimens with impact were fractured from impacted point, as shown by the drop of torque value. It should be noted that first delamination of composite fiber layer occurs then buckling of both aluminum and composite fiber layer seen during failure of hybrid composite specimen under torsion. Torque-twist angle relations were documented for all specimens. Fig. 9 (a) and Fig. 9 (b) shows torquetwist angle relationship for specimens without and with impact damage tested under torsion. The results obtained are outline as follows:

- Bare aluminum tube with and without impact damage endure maximum torsional load of 21.25 $\mathrm{N}$ m \& $34.8 \mathrm{~N}$ m respectively and maximum twisting angle of $4.5^{\circ} \& 7^{\circ}$ respectively.

- Hybrid aluminum/E-glass composite tube with and without impact damage endure maximum torque of $59.2 \mathrm{~N} \mathrm{~m} \mathrm{\&} 79.3 \mathrm{~N}$ m respectively and maximum twisting angle of $11^{\circ} \& 14.5^{\circ}$ respectively.

- Hybrid aluminum/carbon composite tube with and without impact damage endure maximum torque of $48.7 \mathrm{~N} \mathrm{~m} \mathrm{\&} 68.6 \mathrm{~N}$ m respectively and maximum twisting angle of $8.6^{\circ} \& 12.3^{\circ}$ respectively.

\subsection{Bending Strength}

One specimen with no impact damage and one specimen with impact damaged bare aluminum tube were tested under three and four point bending test, similarly done for hybrid glass and carbon tubes. During bending, the damage areas of specimens were kept in upward position. The end supports were considered simply supported and there was no slipping of the specimens over the supports throughout the bending tests. The load vs corresponding deflection of center point could be obtained from the three and four point bending tests. Load- deflection relations were documented for all specimens. Fig. 10 (a) and Fig. 10 (b) shows Loaddeflection relationship for specimens without and with impact damage tested under 3-point bending. In this study, Load- deflection relations were recorded during the test until the applied load reached its maximum value and start decreasing. As load increases visible buckling of top surface and yielding of aluminum commence on the upper half of the specimens at the loading points. Fig.11 (a) and Fig. 11 (b) shows Load-deflection relationship for specimens without and with impact damage tested under 4-point bending.

\section{CONCLUSIONS}

In this experimental study, composite tubes were first damaged by transverse low velocity impact and then tested under torsion and bending tests to understand the effect of damage on torsional and bending strength of hybrid composite tubes. From the above mentioned result the conclusions are summarized as in Table 4:

Table 4:Conclusion

\begin{tabular}{|c|c|c|c|c|}
\hline $\begin{array}{l}\text { Composite tube } \\
\text { specimens }\end{array}$ & $\begin{array}{l}\text { \% reduction in } \\
\text { torsion capacity } \\
\text { due to damage }\end{array}$ & $\begin{array}{l}\% \text { reduction in } \\
\text { twist angle due } \\
\text { to damage }\end{array}$ & $\begin{array}{l}\text { \% reduction in bending } \\
\text { load capacity for three } \\
\text { point bending due to } \\
\text { damage }\end{array}$ & $\begin{array}{l}\text { \% reduction in bending } \\
\text { load capacity for four } \\
\text { point bending due to } \\
\text { damage }\end{array}$ \\
\hline Bare aluminum & 39.02 & 35.7 & 25 & 21.5 \\
\hline Hybrid aluminum/E-glass & 25.42 & 24.13 & 21.42 & 17.64 \\
\hline Hybrid aluminum/carbon & 29 & 30.08 & 23.07 & 18.68 \\
\hline
\end{tabular}



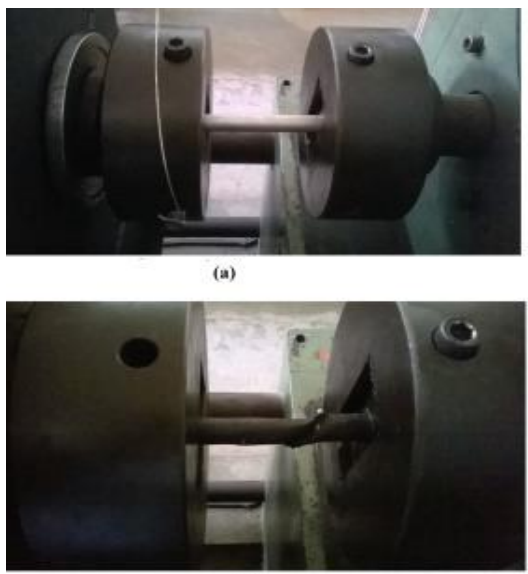

(d)

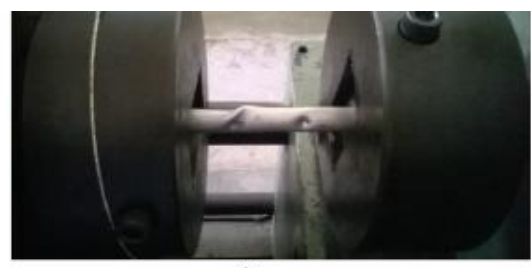

(b)

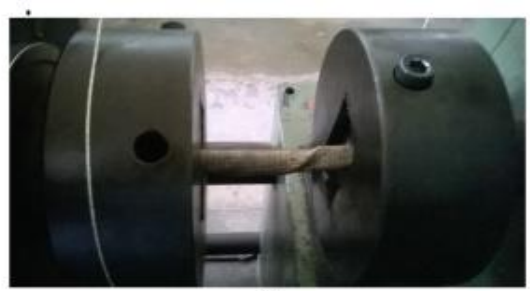

(e)


(f)

Fig. 6:Specimen loaded under torsion (a) Al tube without impact (b) Al tube with impact (c) hybrid Al/carbon specimen without impact (d) hybrid Al/carbon specimen with impact (e) hybrid Al/glass specimen without impact and (f) hybrid Al/ glass specimen with impact

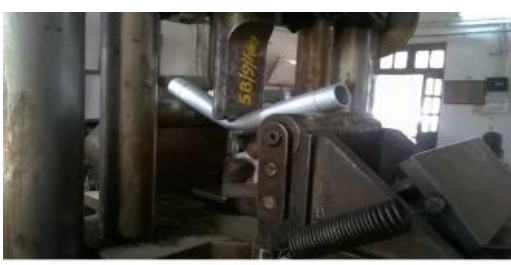

(a)

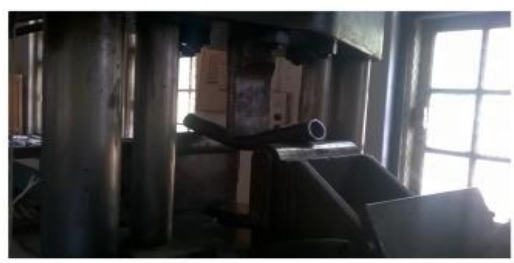

(d)

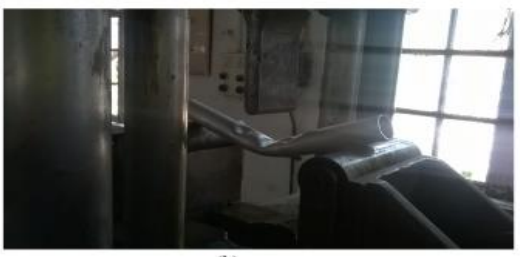

(b)

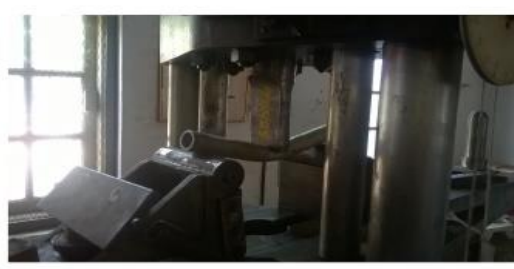

(e)

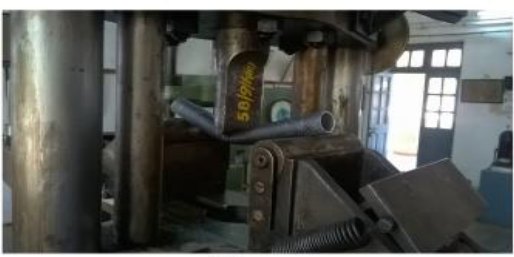

(c)

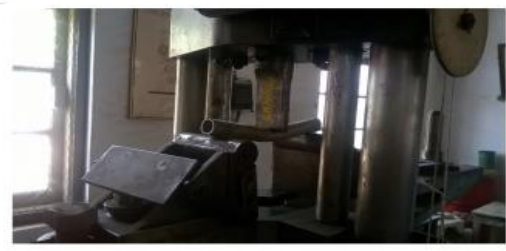

(f)

Fig. 7:Specimen loaded under 3-point bending (a) Al tube without impact (b) Al tube with impact (c) hybrid $\mathrm{Al} /$ carbon specimen without impact (d) hybrid Al/carbon specimen with impact (e) hybrid Al/glass specimen without impact and (f) hybrid Al/ glass specimen with impact

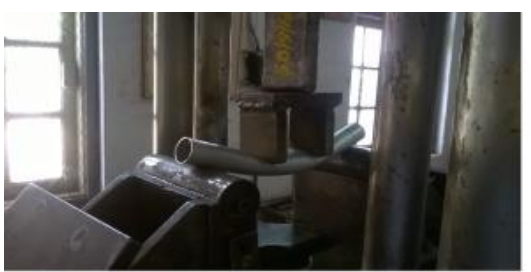

(a)

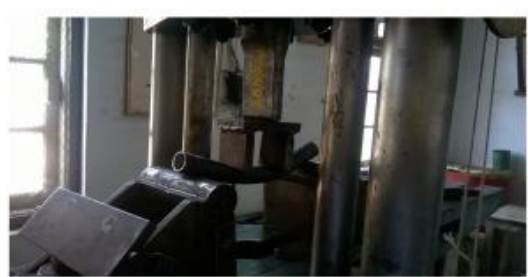

(d)

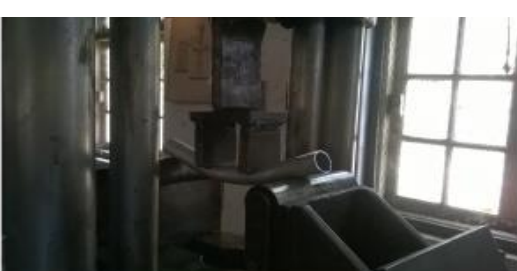

(b)

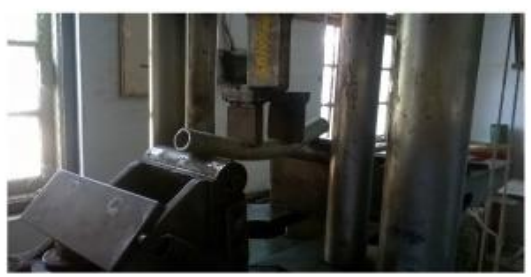

(e)

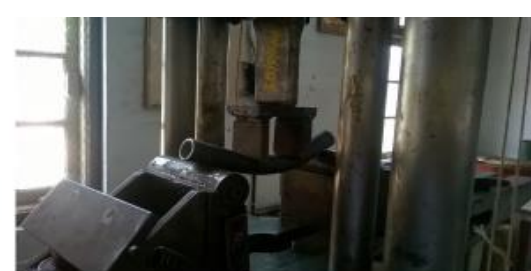

(c)

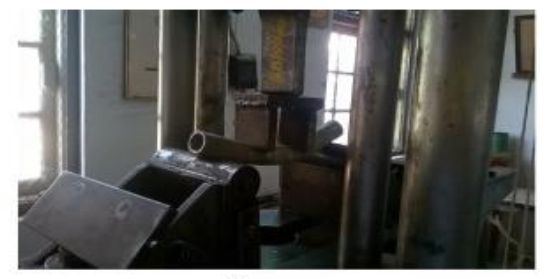

Fig. 8:Specimen loaded under 4-point bending (a) Al tube without impact (b) Al tube with impact (c) hybrid $\mathrm{Al} /$ carbon specimen without impact (d) hybrid Al/carbon specimen with impact (e) hybrid Al/glass specimen without impact and (f) hybrid Al/ glass specimen with impact 


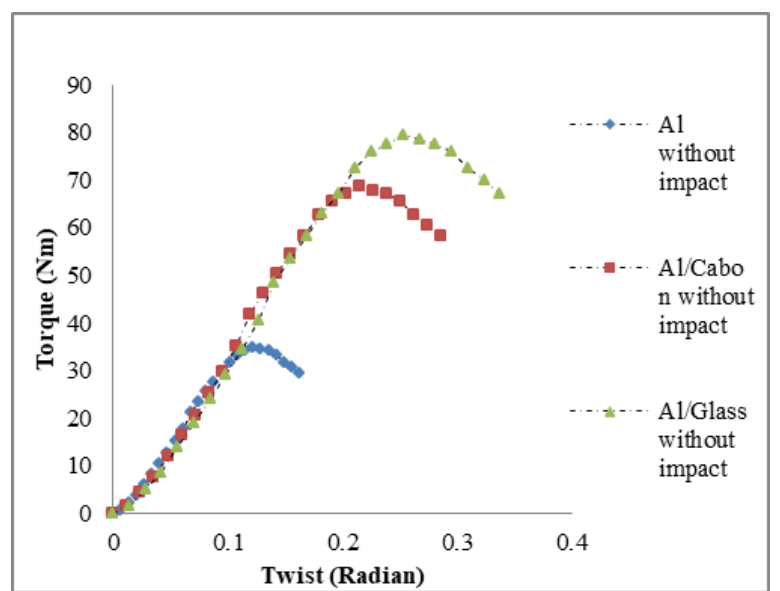

Fig. 9(a) Torque-twist angle relationship for specimens without impact damage tested under torsion



Fig. 9(b) Torque-twist angle relationship for specimens with impact damage tested under torsion

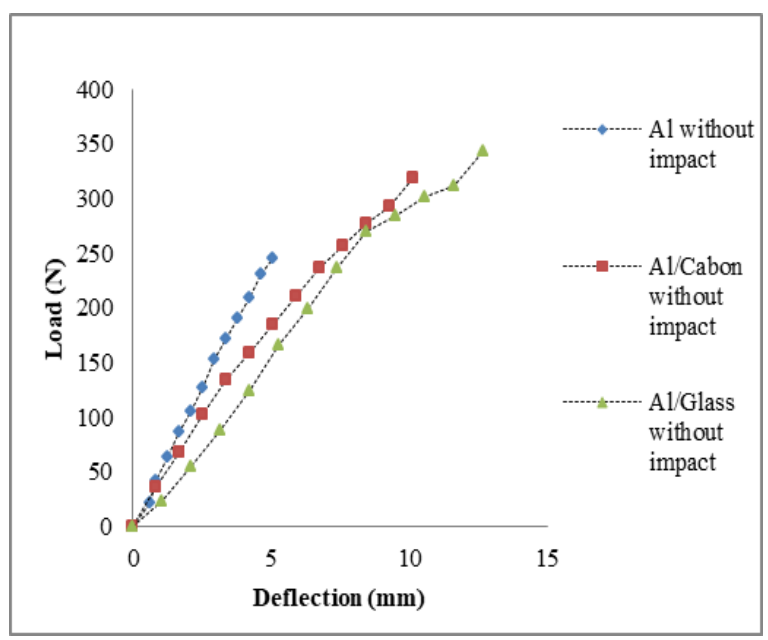

Fig. 10(a) Load- deflection relationship for specimens without impact damage tested under 3point bending

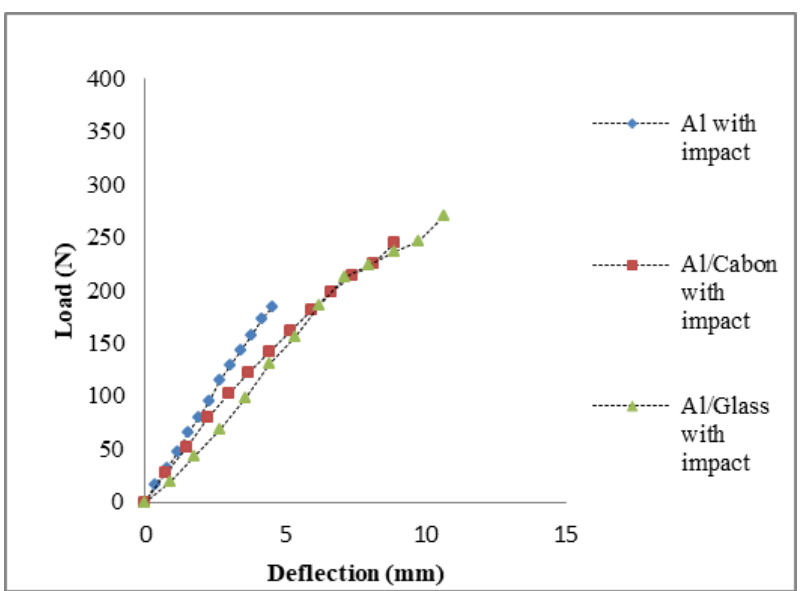

Fig. 10(b) Load- deflection relationship for specimens with impact damage tested under 3point bending

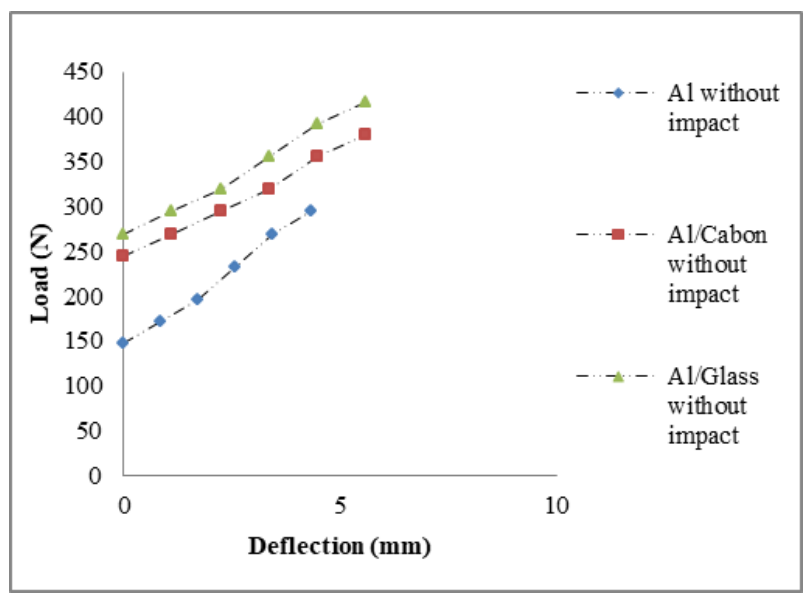

Fig. 11(a) Load- deflection relationship for specimens without impact damage tested under 4point bending

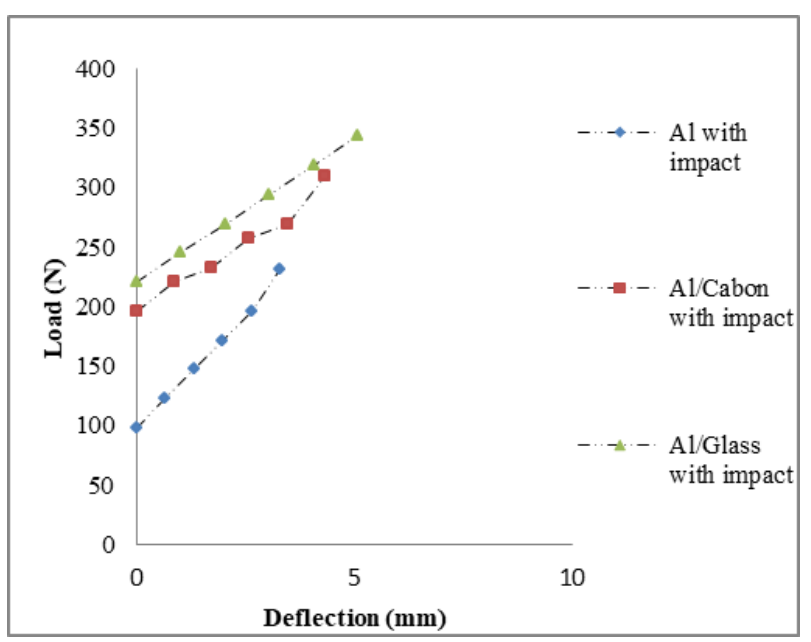

Fig. 11(b) Load- deflection relationship for specimens with impact damage tested under 4point bending 


\section{REFERENCES}

[1]. A.R. Abu Talib , Aidy Ali, Mohamed A. Badie, NurAzidaCheLah, A.F. Golestaneh, "Developing a hybrid, carbon/glass fiberreinforced, epoxy composite automotive drive shaft" Materials and Design 31 (2010) 514 521

[2]. M.A. Badie, E. Mahdi, A.M.S. Hamouda, "An investigation into hybrid carbon/glass fiber reinforced epoxy composite automotive drive shaft" Materials and Design 32 (2011) $1485-1500$

[3]. S.A. Mutasher, "Prediction of the torsional strength of the hybrid aluminum/composite drive shaft" Materials and Design 30 (2009) 215-220

[4]. Y.A. Khalid, S.A. Mutasher, B.B. Sahari, A.M.S. Hamouda, "Bending fatigue behavior of hybrid aluminum/composite drive shafts" Materials and Design 28 (2007) 329-334

[5]. Durk Hyun Cho, Dai Gil Lee, Jin Ho Choi, "Manufacture of one-piece automotive drive shafts with aluminium and composite materials" Composite structure Vol. 38, No. l-4, (1997) pp. 309-319, 1997

[6]. Dai Gil Lee, Hak Sung Kim, Jong Woon Kim, Jin Kook Kim, "Design and manufacture of an automotive hybrid aluminum/composite drive shaft" Composite Structures 63 (2004) 87-99

[7]. S. Misri, S.M. Sapuan, Z. Leman, M.R. Ishak, "Torsional behavior of filament wound kenaf yarn fibre reinforced unsaturated polyester composite hollow shafts" Materials and Design, Volume 65, (2015), 953-960

[8]. Ercan Sevkat, Hikmet Tumer, M. Halidun Kelestemur, Selim Dogan, "Effect of torsional strain-rate and lay-up sequences on the performance of hybrid composite shafts" Materials and Design 60 (2014) 310-319

[9]. Mahmood M. Shokrieh, Akbar Hasani, Larry B. Lessard, "Shear buckling of a composite drive shaft under torsion" Composite Structures 64 (2004) 63-69

[10]. O. Montagnier, Ch. Hochard, "Optimization of hybrid high-modulus/high-strength carbon fibre reinforced plastic composite drive shafts" Materials and Design 46 (2013) 88100

[11]. Ercan Sevkat, Hikmet Tumer, "Residual torsional properties of composite shafts subjected to impact loadings" Materials and Design 51 (2013) 956-967

[12]. G. Minak, S. Abrate, D. Ghelli, R. Panciroli, Zucchelli, "Low-velocity impact on carbon/epoxy tubes subjected to torque -
Experimental results, analytical models and FEM analysis" Composite Structures 92 (2010) 623-632

[13]. G. Minak, S. Abrate, D. Ghelli, R. Panciroli, A. Zucchelli, "Residual torsional strength after impact of CFRP tubes" Composites: Part B 41 (2010) 637-645

[14]. Ahmed M. El-Assal, U.A. Khashaba, "Fatigue analysis of unidirectional GFRP composites under combined bending and torsional loads" Composite Structures 79 (2007) 599-605

[15]. A. B. Doyum, B. Altay, "Low-velocity impact damage in glass fibre/epoxy cylindrical tubes" Materials \& Design, Vol. 18, No. 3, (1997) pp.131-135

[16]. Aniruddha Mitra, Sirajus Salekeen, Mosfequr Rahman, "Fabrication of polyurethane based fabric composite shaft and its experimental study under triple point bending" Proceedings of the ASME International Mechanical Engineering Congress \& Exposition (2012) 915

[17]. http://www.nptel.ac.in/courses/101106038/ 